\title{
UNIFORM GENETIC DIVERSITY, LOW DIFFERENTIATION, AND NEUTRAL EVOLUTION CHARACTERIZE CONTEMPORARY REFUGE populations of Taiwan fir (Abies kawakamit, Pinaceae) ${ }^{1}$
}

\author{
Fu-Lung Shih, ${ }^{2}$ Shim-Ying Hwang, ${ }^{3}$ Yu-Pin Cheng, ${ }^{2}$ Pei-Fen Lee, ${ }^{4}$ and Tsan-Piao Lin ${ }^{2,5}$ \\ ${ }^{2}$ Institute of Plant Biology, National Taiwan University, Taipei 106, Taiwan; ${ }^{3}$ Graduate Institute of Biotechnology, \\ Chinese Culture University, Yangmingshan, Taipei 111, Taiwan; and ${ }^{4}$ Institute of Ecology and Evolutionary Biology, \\ National Taiwan University, Taipei 111, Taiwan
}

\begin{abstract}
Based on fossil pollen, the distribution range of Taiwan fir [Abies kawakamii (Hay.) Ito] (Pinaceae) is smaller than it was 50000 years ago. To characterize the present refuge populations of A. kawakamii, which survive only in subalpine forests in Taiwan, we surveyed nuclear genes and chloroplast intergenic spacers to assess the genetic diversity of Taiwan fir. Populations maintain high genetic diversity and contain similar numbers of haplotypes for the GapC (cytosolic glyceraldehyde 3-phosphate dehydrogenase) fragment. Haplotypes for GapC are generally widespread, and population-specific haplotypes accounted for $2.5 \%$ of the total. Differentiation among populations is very low $\left(G_{\mathrm{ST}}=0.01\right)$. Only three haplotypes were detected for the cpDNA marker, and every population had one or two haplotypes. In a neutrality test, the variation in nucleotides did not deviate from that expected with neutral evolution for either marker. A retreat route to higher elevations was not evident from either the GapC or cpDNA markers. Hsuehshan was the site of the most divergent population in Taiwan. We concluded that uniform genetic diversity, low differentiation, low numbers of population-specific haplotypes, and neutral evolution characterize contemporary refuge populations of Taiwan fir.
\end{abstract}

Key words: Abies kawakamii; genetic divergence; glyceraldehyde 3-phosphate dehydrogenase; phylogeography; Pinaceae; refugium; Taiwan; $t r n L-t r n F$ intergenic spacer.

The advance and retreat of glaciers have significantly influenced the distribution and diversity of plant species. The massive climatic changes associated with glaciation led to large-scale migrations and reductions in populations followed by colonization and population expansion as the glaciers retreated (Pielou, 1991). In the northern hemisphere, temperate zone species are believed to have survived these unfavorable episodes in refugial areas before expanding their ranges during the present interglacial period (Hewitt, 2000; Taberlet and Cheddadi, 2002; Abbott and Brochman, 2003). At northerly latitudes, there are immense territories for recolonization. A different situation exists in subtropical regions where subtropical and temperate species live at different elevations. During the Ice Ages, it is believed that subtropical plants might have been forced into refuge sites, whereas the lowlands became suitable environments for temperate plants (Tsukada, 1967).

In Taiwan, the subalpine forests are restricted to 2500-3700 $\mathrm{m}$ a.s.l., and Taiwan fir [Abies kawakamii (Hay.) Ito], the only Taiwanese species in the genus, is the dominant tree between 3000 and $3500 \mathrm{~m}$ a.s.l. throughout the region. Taiwan fir is adapted to a cold, humid environment at high elevations and typically occurs in sheltered to windswept sites (Huang, 2002). Trees form pure stands or patches and are always accompanied by characteristic shrubs and herbs, especially Yushania

\footnotetext{
${ }^{1}$ Manuscript received 21 July 2006; revision accepted 21 November 2006. The authors are indebted to Mr. S. Huang for collecting Abies spectabilis from Deurali, Nepal, where he made a field trip in March 2005. This investigation was funded by a grant (NSC92-3114-B-002-005) from the National Science Council, Executive Yuan, Taiwan.

${ }^{5}$ Author for correspondence (e-mail: tpl@ntu.edu.tw); present address: National Taiwan University, Institute of Plant Biology, No. 1 Roosevelt Road, Section 4, Taipei 106, Taiwan; fax: 886-2-23689564
}

niitakayamensis (Hay.) Keng (Poaceae), which prefers relatively open canopies. In Abies forests at lower elevations (2500$3000 \mathrm{~m}$ a.s.l.), the following four conifers are usually found growing sporadically in association with Taiwan fir: Taiwan Armand pine (Pinus armandii Fr. var. mastersiana Hay.), Taiwan hemlock [Tsuga chinensis Pritz. var. formosana (Hay.)], Taiwan spruce (Picea morrisonicola Hay.), and mountain juniper [Juniperus squamata Lamb. var. morrisonicola (Hay.) Li et Keng]. Abies kawakamii is one of 40 fir species worldwide but has received little attention. The total area covered by Taiwan fir is believed to be less than 20000 ha (Taiwan Forest Bureau, 1995), apparently because the world is currently in an interglacial stage, a very restricted range; thus it is endangered.

Taiwan is thought to have been connected to the Asian continent during the glacial maximum in the late Pleistocene (Boggs et al., 1979). A more-recent land configuration proposed for the late Pleistocene $(0.2-0.02$ million years ago [Ma]) indicates that a large land bridge extended from eastern China to Taiwan, the Ryukyus, and probably to the main islands of Japan (Kimura, 1996), which would have provided the opportunity for gene flow among haplotypes. Most of the flora of Taiwan is thought to have originated from the Asian mainland during cycles of temperature oscillations. Although the land in Taiwan has never been covered by ice sheets except on the highest peaks, the tremendous temperature and climatic changes should have influenced species distributions and evolution. Palynological records from a lake core at an elevation of $745.5 \mathrm{~m}$ a.s.l. in central Taiwan suggest that the temperature during the last glacial age was $8.0-11.0^{\circ} \mathrm{C}$ cooler than today and that the lowland vegetation was dominated by cool-temperate species and boreal elements (Tsukada, 1966, 1967). Taiwan fir was one of the dominant species of the boreal element between 50000 and 60000 years Ma (covering the time span of the maximal Tali glaciation), at which time 
Taiwan fir was widespread over low elevations. During the last 50000 years Ma, Taiwan fir has again recolonized higher elevations. Such a contraction-expansion model is well documented by pollen records in Europe and North America (Taberlet and Cheddadi, 2002), but evidence for this is largely lacking in Taiwan.

Subtropical and warm-temperate species that now comprise large areas of the lowland and montane vegetation are undergoing population expansion and colonization. In Taiwan, glacial refugia were predicted to have occurred in two regions: north-central Taiwan and southern Taiwan (Huang et al., 2002; Chung et al., 2004). In a previous report, we used chloroplast DNA sequences to document that the southeastern part of Taiwan may have been a potential refugium for lowland plants during the last glacial stage (Huang et al., 2002). Another potential refuge site for subtropical and temperate plant species was localized in the Hsuehshan Range in north-central Taiwan (Chung et al., 2004; Huang et al., 2004).

Nuclear DNA is considered the fastest evolving among the three genomes in the cell (Wolfe et al., 1987). In most phylogeographical studies in plants, cytoplasmic DNA has been used to characterize population structure and evolutionary history, and only limited use has been made of nuclear genes as a marker, i.e., glyceraldehyde 3-phosphate dehydrogenase (Olsen and Schaal, 1999; Tani et al., 2003) and vacuolar invertase (Caicedo and Schaal, 2004). Studies with these traditional phylogeographical goals often use nuclear data to corroborate initial results based on cytoplasmic loci (Hare, 2001). Even though the genealogical tree constructed using nuclear genes may contain errors introduced by recombination (Schierup and Hein, 2000), selection, and allelic discrimination (Zhang and Hewitt, 2003), nuclear genes can more completely reveal the mosaic of genealogical patterns evolving in genomes in response to historical and environmental conditions (Hare, 2001).

In typical phylogeographic studies, descriptions of population expansion from refuges have been based on pollen fossil and molecular evidence in temperate regions (Comes and Kadereit, 1998; Hewitt, 2000). In fact, several relictual conifers in subtropical Mexico are of great relevance to this study. Examples include studies of four species of Abies (AguirrePlanter, 2000), two species of Picea (Ledig et al., 2000, 2002), Pinus nelsonii (Cuenca et al., 2003), P. maximartinezii (Ledig et al., 1999), and P. sylvestris (Robledo-Arnuncio et al., 2005) in refugial populations of Spain. The objective of this study was to characterize the population structure and evolutionary history of A. kawakamii in Taiwan using chloroplast DNA and nuclear genes. We hypothesized that the high-mountain region is the contemporary refuge for Taiwan fir and other species. Results of the phylogeographical analysis in this study revealed selected genetic characteristics of a refuge population of an extant plant species.

\section{MATERIALS AND METHODS}

Sampling of plant populations-Leaves of A. kawakamii were collected from eight populations in Taiwan (Table 1). The Hsuehshan and Tapachienshan populations represent the Hsuehshan Range, and the remaining populations represent the Central Mountain Ridge. Yushan reaches the highest elevation (3954 m a.s.1.) in East Asia. Eight individuals were sampled for each population, except only six were sampled for Wumingshan and seven for Yushan. One sample of A. spectabilis collected from Deurali, Nepal $\left(83.73^{\circ} \mathrm{E}\right.$, $28.55^{\circ} \mathrm{N}$ ) was also analyzed.
Polymerase chain reaction (PCR) and sequencing-DNA was extracted from foliage with the following modification of a standard protocol (Murray and Thompson, 1980). For chloroplast genes, we tested four pairs of primers (Table 2). For nuclear genes, one pair of primers was designed according to the GapC intron sequence of three Japanese Abies species (Isoda and Shiraishi, 2001). Mitochondrial DNA was also tested with two universal primers (Demesure et al., 2000). The PCR using these primers could amplify a partial sequence corresponding to intron 2 of nadl. A chloroplast microsatellite, which was shown to be polymorphic in several Abies species (Parducci et al., 2001), was amplified using the Pt30204 primer pair. The PCR solution was prepared as follows: $500 \mathrm{mM} \mathrm{KCl}, 15 \mathrm{mM} \mathrm{MgCl} 2,0.01 \%$ gelatin, $100 \mathrm{mM}$ Tris- $\mathrm{HCl}(\mathrm{pH}$ 8.3), $250 \mu \mathrm{M}$ of each dNTP, $2 \mu \mathrm{M}$ of each primer, 0.04-20 ng template DNA, 1 $\mu \mathrm{g}$ RNase, 0.5 unit Taq polymerase (Amersham Biosciences, Taipei, Taiwan), and double-distilled water to a final volume of $10 \mu \mathrm{L}$. Amplifications were performed with an initial denaturing of $2 \mathrm{~min}$ at $95^{\circ} \mathrm{C}$, then 35 cycles of $1 \mathrm{~min}$ at $95^{\circ} \mathrm{C}, 90 \mathrm{~s}$ at $62^{\circ} \mathrm{C}$, and $2 \mathrm{~min}$ at $72^{\circ} \mathrm{C}$, followed by a 9 -min extension at $72^{\circ} \mathrm{C}$.

Nucleotide sequences were determined by direct sequencing of the purified PCR products on an ABI 3300 Genetic Analyzer with BigDye terminator cycle sequencing reagents (Applied Biosystems, Foster City, California, USA). This was applied to sequences of homozygotes or sequences containing few polymorphic sites. Clones, however, were sequenced for each individual when sequences contained many polymorphic sites and indels (pGEM-T Easy Vector System I; Promega Madison, Wisconsin, USA). The two sequences of a heterozygote were differentiated by comparing the sequences of the PCR products to those of the cloned colony to avoid error from Taq polymerase (Okuyama et al., 2005). The evidence suggested that the present GapC haplotypes were derived from a single gene. No more than two haplotypes were identified per individual (as would be expected for a diploid nuclear gene).

Genealogical analyses - Sequence alignment was performed using CLUSTAL W (Thompson et al., 1994) with manual adjustment. Haplotypes and their relationships were determined using the computer program TCS, version 1.06 (Templeton et al., 1992), and fragments of insertions or deletions (indels) in sequences were treated as a single mutation event. Nucleotide diversity, haplotype diversity, tests of neutrality, and determination of associated significance were carried out using the program DnaSP, version 4.10 (Rozas et al., 2003). Haplotype (gene) diversity and its sampling variance were based on Nei (1987, eqs. 8.4 and 8.12). The standard deviation is the square root of the variance. Nucleotide diversity, $\pi$, the average number of nucleotide differences per site between two sequences, was based on Nei (1987, eqs. 10.5 or 10.6), and its sampling variance was based on equation 10.7. The standard deviation (or standard error) is the square root of the variance. Tests for departure from neutrality on the total number of segregating sites were based on the $D$ test of Tajima (1989) and the $D^{*}$ and $F^{*}$ tests of Fu and Li (1993). To survey possible recombination events, the minimum number of recombination events (Rm) based on the four-gamete test (Hudson and Kaplan, 1995) was estimated using the DnaSP, version 4.10 (Rozas et al., 2003).

Analysis of the population substructure - Measures of diversity $\left(G_{\mathrm{ST}}\right)$ and differentiation $\left(N_{\mathrm{ST}}\right)$ were analyzed using the program Hapstep (Pons and Petit, 1996). $G_{\mathrm{ST}}$ depends only on the frequencies of the haplotypes. However, $N_{\mathrm{ST}}$ is influenced by both haplotype frequencies and the distances between haplotypes. Distances between haplotypes were calculated according to the number of mutational steps separating the paired haplotypes. Thus, the amount of substructure $\left(N_{\mathrm{ST}}\right)$ can be calculated. A test of the matrix of pairwise genetic distance against the matrix of pairwise geographic distance was performed using a software tool for simple and partial Mantel tests (Bonnet and Van de Peer, 2002). The geographic distance between populations was calculated using Excel (Microsoft, Redmond, Washington, USA), and the latitudes and longitudes in Table 1 . To test if genetic differentiation might be geographically related, we separated populations into four groups and tested them with analysis of molecular variance (AMOVA) (Excoffier et al., 1992). AMOVA with statistical significance was determined by permutation analyses to partition genetic variation at different levels. Significance was determined by 1000 permutations.

The genetic distance, $D_{\mathrm{XY}}$ (Nei, 1987, eq. 10.20), incorporating the allelic frequencies for compared populations, and the mean number of nucleotide substitutions per site between populations using a one-parameter substitution model (Jukes and Cantor, 1969) were estimated using DnaSP version 4.10 (Rozas et al., 2003). Thus, $D_{\mathrm{xy}}$ provides more information than $F_{\mathrm{ST}}$ regarding divergence comparisons. In addition, the amount of divergence for each 
TABle 1. Populations, sample sizes $(N)$, and haplotypes based on the GapC intron of Abies kawakamii in Taiwan.

\begin{tabular}{|c|c|c|c|}
\hline Population & Location & $N$ & Haplotypes (No. alleles) \\
\hline Hsuehshan (Sy) & $121.23^{\circ} \mathrm{E}, 24.38^{\circ} \mathrm{N}$ & 8 & $\mathrm{~A}(2), \mathrm{B}(2), \mathrm{C}(7), \mathrm{D}(1), \mathrm{E}(3), \mathrm{I}(1)$ \\
\hline Nanhutashan $(\mathrm{Na})$ & $121.42^{\circ} \mathrm{E}, 24.37^{\circ} \mathrm{N}$ & 8 & $\mathrm{~A}(6), \mathrm{B}(6), \mathrm{C}(1), \mathrm{D}(1), \mathrm{E}(1), \mathrm{G}(1)$ \\
\hline Hohuanshan (Ho) & $121.27^{\circ} \mathrm{E}, 24.15^{\circ} \mathrm{N}$ & 8 & $\mathrm{~A}(8), \mathrm{B}(5), \mathrm{C}(1), \mathrm{E}(1), \mathrm{F}(1)$ \\
\hline Chilaishan $(\mathrm{Ch})$ & $121.33^{\circ} \mathrm{E}, 24.08^{\circ} \mathrm{N}$ & 8 & A (7), B (5), D (1), E (1), F (2) \\
\hline Yushan $(\mathrm{Yu})$ & $120.93^{\circ} \mathrm{E}, 23.47^{\circ} \mathrm{N}$ & 7 & A (5), B (3), C (1), E (1), F (2), H (2) \\
\hline
\end{tabular}

population from the remaining populations was calculated as the mean of the pairwise values of $D_{\mathrm{xy}}$ for each population against the remaining populations.

Spatial AMOVA (SAMOVA) was used to identify the population groups that maximized the proportion of total genetic variance (Dupanloup et al., 2002). SAMOVA was undertaken assuming two, three, four, five, or six groups as simulated by the SAMOVA program version 1.0 (Dupanloup et al., 2002).

\section{RESULTS}

Sequence analyses and distribution patterns of chloroplast DNA markers - We sequenced the nadl fragment of mitochondrial DNA in random samples from different populations and found no variation in nucleotide sequences (data not shown). One chloroplast microsatellite (Pt30204) was tested using randomly selected individuals, and all of them contained 19T. We then sequenced four fragments of cpDNA (intergenic spacers $\operatorname{trn} T$-trnL, $\operatorname{trn} R$-trn $G$, and $\operatorname{trn} L$-trnF and coding region $r b c L$ ), and only a few polymorphic sites were found (Table 2). Fragment trnL-trnF generated three haplotypes: kawakamiil was the most abundant one; kawakamii2 occurred in one individual each from the Nanhutashan, Hohuanshan, Chilaishan, and Kuanshan populations; and kawakamii3 occurred in one individual from Hsuehshan. Therefore, each population had either one or two haplotypes.

Sequence and genealogical analysis of the GapC intron gene-We amplified an intron of the GapC (cytosolic glyceraldehyde 3-phosphate dehydrogenase) gene of 603 base pairs (bp). In total, 122 sequences of 61 individuals were obtained, and $67 \%$ of the samples were heterozygous. Ten haplotypes were assigned from A to J (with GenBank accession nos., Table 3). Haplotype $\mathrm{H}$ has an insertion of
194 bp beginning at bp 442, and the insertion was transformed by a one-step substitution. The genealogical relationships of these haplotypes are shown in Fig. 1, and the number of alleles containing various haplotypes are shown in Table 1. Possible recombinations were investigated by the minimum number of recombination events $(\mathrm{Rm})$ based on the four-gamete test (Hudson and Kaplan, 1995). In a number of 153 pairwise comparisons, no recombination event was detected in the aligned GapC sequences of 10 haplotypes. Therefore, only one GapC genealogy was derived from the TCS analysis.

Taiwan fir appears to have the closest relationship with $A$. homolepis (Kormutak and Yang, 1998; Xiang et al., 2004). Fortunately, several DNA sequences of the GapC of A. firma, A. homolepis, and A. veitchii of Japan (Isoda and Shiraishi, 2001) were found to be available in the National Center for Biotechnology Information (NCBI) databank and were used in addition to $A$. spectabilis from Nepal (accession nos.: Ne1, DQ116587 and Ne2, DQ116588) as outgroups to determine the ancestral haplotype of $\mathrm{GapC}$ in Taiwan fir. The haplotypes of the first two species from Japan were rejected by the TCS tree, and the haplotype of $A$. spectabilis was found to be inserted between haplotypes A and C. Abies veitchii of Japan formed another independent branch. Haplotypes $\mathrm{F}$ and $\mathrm{H}$ of $A$. kawakamii were derived from another A. spectabilis.

Distribution patterns of haplotypes-Mapping geography onto the haplotype network of GapC produced a complicated pattern (Fig. 1). Among the 10 haplotypes found in Taiwan, haplotypes $\mathrm{A}$ and $\mathrm{B}$ accounted for $63 \%$ (77 of 122 alleles) of the total. These two haplotypes were spread throughout Taiwan's populations (Fig. 1, Table 1). Most populations had six haplotypes, and most were generally widely distributed. In

TABLE 2. Primer pairs for chloroplast and nuclear DNA used in this study. Haplotypes and accession numbers are listed for Abies kawakamii.

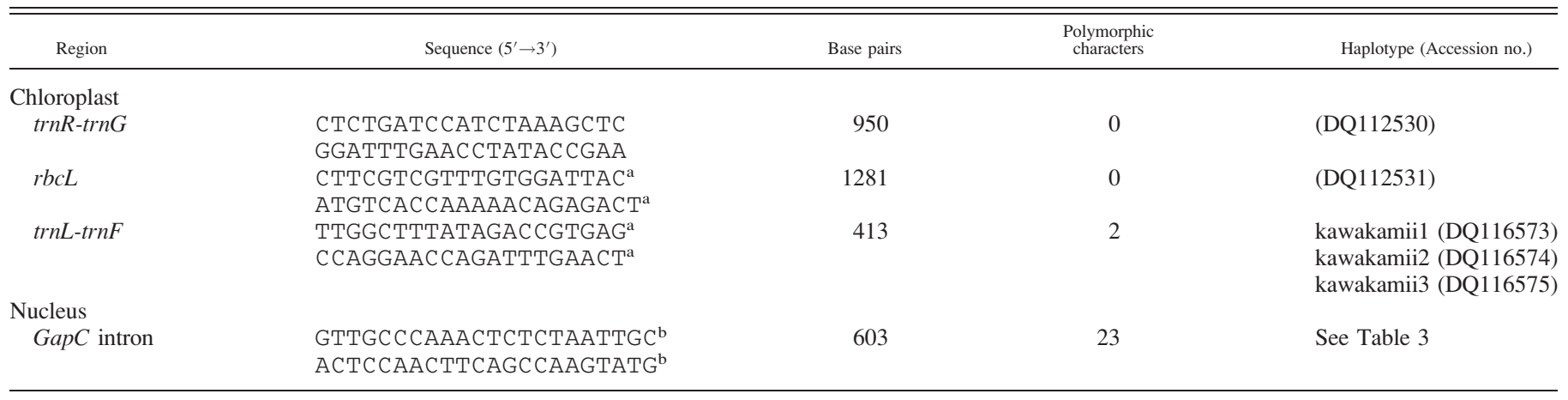

${ }^{a}$ Refer to Suyama et al. (2000).

$\mathrm{b}$ These were designed based on the GapC intron sequence of three Japanese Abies species (Isoda and Shiraishi, 2001). 
TABLE 3. Haplotypes and accession numbers of Abies kawakamii according to mutations of the $\mathrm{GapC}$ intron.

\begin{tabular}{|c|c|c|}
\hline $\begin{array}{c}\text { Haplotype } \\
\text { (Accession no.) }\end{array}$ & No. alleles & $\begin{array}{l}\text { Mutation site of haplotype } \\
0000111112222222233444555 \\
0559124791155667789156359669 \\
3780676052467890299862876670\end{array}$ \\
\hline A (DQ116577) & 42 & GCATCTTCGTC--CTTCAGGATCGT--G \\
\hline B (DQ116578) & 35 & GCATCTTCATC--CTTCAAGATCAT--G \\
\hline C (DQ116579) & 13 & АCATCTTCGTC--CTTCAAGATCGT--G \\
\hline D (DQ116580) & 9 & GCAGCTTCGTC--CTTCAGGATCGT--G \\
\hline E (DQ116581) & 9 & G--TTTTCGACCTCTTTTAGA-CATTTG \\
\hline F (DQ116582) & 6 & GCATCTCGGTCCTCTTCAAAG-CAG--T \\
\hline G (DQ116583) & 3 & GCATCTTCATC-----CAAGATCAT--G \\
\hline H (DQ116584) & 2 & GCATCTCGGTCCTCTTCAAAA-GAT--T \\
\hline I (DQ116585) & 2 & АCATCTTCGTT--CTTCAAGATCGT--G \\
\hline J (DQ116586) & 1 & GCATCCTCATC--CTTCAAGATCAT--G \\
\hline
\end{tabular}

contrast, haplotype $\mathrm{H}$ was only found at Yushan; haplotype I was found at Hsuehshan and Tapachienshan; and haplotype J, a singleton, was only found at Tapachienshan. Thus, populationspecific alleles accounted for $2.5 \%$ of the total haplotypes. The rare $\mathrm{I}$ and $\mathrm{J}$ haplotypes both appeared at Hsuehshan and Tapachienshan, which represent the Hsuehshan Range, and might reflect the separation of the Hsuehshan Range from the Central Mountain Range, which contained the remaining populations.

Analysis of the population genetic structure-For the GapC intron sequences, genetic differentiation among populations $\left(G_{\mathrm{ST}}\right)$ was $0.010( \pm 0.0280), H_{\mathrm{S}}$ (intrapopulational diversity) was $0.773( \pm 0.0198)$, and $H_{\mathrm{T}}$ (total diversity) was 0.781 ( \pm 0.0305$)$. The degree of substructure, $N_{\mathrm{ST}}$, was 0.015 . The value of $N_{\mathrm{ST}}-G_{\mathrm{ST}}$ of 0.005 was not significant. Thus, the spatial genetic patterning was determined to be very weak. Moreover, genetic distances did not correlate with geographic

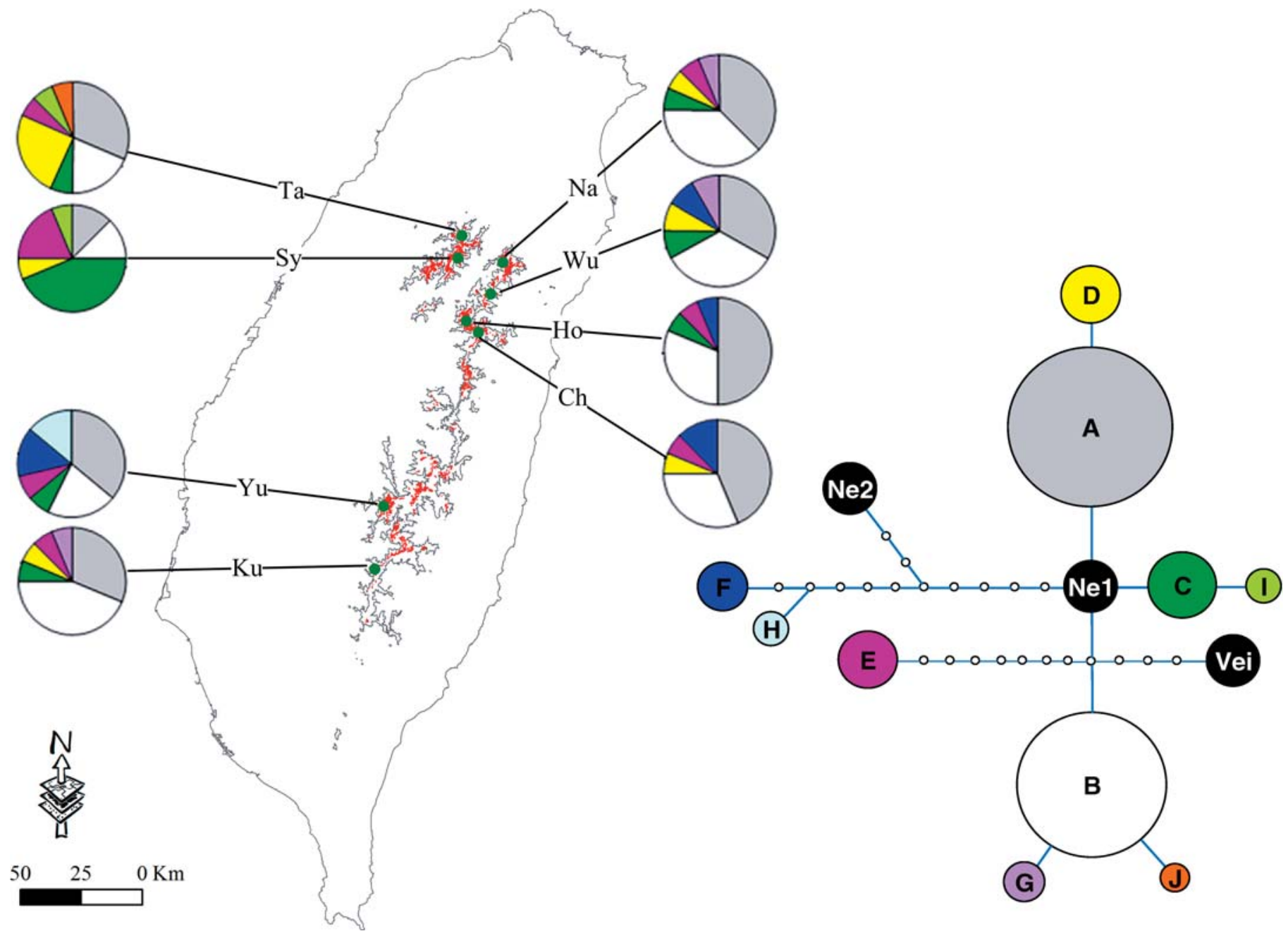

Fig. 1. Map of the geographical distribution of the GapC haplotypes and the proportions of each haplotype in each population of Abies kawakamii in Taiwan. Only elevations above $2700 \mathrm{~m}$ a.s.l. in the mountains are shown. Red dots represent locations of Taiwan fir. Colors indicate different haplotypes that are shown in the gene tree. Relationships of haplotypes of the nuclear gene marker GapC (unrooted) reconstructed by the computer program TCS v. 1.06 (Templeton et al., 1992) are shown on the right. Haplotypes indicated by circles of variable sizes reflect the numbers of alleles found. A dot represents a mutation for which a haplotype was not found within the sample. Ne1 and Ne2, two haplotypes of A. spectabilis of Nepal; Vei, haplotype of A. veitchii of Japan (Isoda and Shirashi, 2001). Haplotypes of A. firma and A. homolepis were excluded from the network. 
TABLE 4. Analysis of molecular variance based on the GapC sequences of Abies kawakamii in Taiwan. Populations were divided into four groups: Tapachienshan and Hsuehshan, Nanhutashan and Wumingshan, Hohuanshan and Chilaishan, and Yushan and Kuanshan. Levels of significance are based on 1000 random permutations.

\begin{tabular}{lrrrr}
\hline \hline \multicolumn{1}{c}{ Source of variation } & df & MSD & $\begin{array}{c}\text { Variance } \\
\text { components }\end{array}$ & $\begin{array}{c}\text { Percentage } \\
\text { of total }(P)\end{array}$ \\
\hline Among groups & 3 & 9.848 & 0.03174 & $1.56(0.21408)$ \\
Among populations within groups & 4 & 9.249 & 0.02198 & $1.08(0.28641)$ \\
Within populations & 114 & 225.601 & 1.97896 & 97.36 \\
Total & 121 & 244.698 & 2.03267 & - \\
\hline
\end{tabular}

Note: MSD, mean squared deviation.

distances based on the results of the Mantel test for $D_{\mathrm{XY}}(r=$ $0.110998, P=0.319868)$. We suspect that populations of the Hsuehshan Range and the Central Mountain Range may greatly differ, so populations were divided into four groups for further testing. Genetic differentiation among groups was low as assessed by the AMOVA, and more than 97\% of the variance resided within populations (Table 4).

Nucleotide diversities $(\pi)$ were extremely low for the cpDNA marker (data not shown). Values for haplotype diversity and nucleotide diversity varied from 0.68 to 0.83 and from 0.0050 to 0.0098 , respectively, for the GapC marker (Table 5). The Yushan (Yu) population had the highest nucleotide diversity, followed by Hsuehshan (Sy), whereas Kuanshan $(\mathrm{Ku})$, a marginal population, had the lowest value. The Tapachienshan (Ta) population had the highest haplotype diversity because of the seven haplotypes recovered, followed by Yushan. Overall, the DNA variation among populations in Taiwan did not deviate from the expectation of neutrality, according to Tajima's criterion $(D=-0.24877, P>0.05)$ and the Fu and Li tests $\left(D^{*}=1.39979, P>0.05 ; F^{*}=0.91182, P\right.$ $>0.05)$ (Table 5). The same tests were applied to the chloroplast $\operatorname{trnL}$-trnF sequences, and again, the DNA variation of populations did not deviate from the expectation of neutrality, according to Tajima's criterion $(D=-1.07583, P$ $>0.05)$ and the $\mathrm{Fu}$ and Li tests $\left(D^{*}=-0.94732, P>0.05 ; F^{*}\right.$ $=-1.14678, P>0.05)$.

Pairwise $D_{X Y}$ statistics according to nucleotide differences and population divergence - The mean $D_{\mathrm{XY}}$ values according to the GapC intron of each population compared with every other population were small and varied from 0.0058 (Nanhutashan) to 0.0083 (Yushan). Two peaks of average $D_{\mathrm{XY}}$ values were found at Yushan and Hsuehshan (0.0073) (Fig. 2). The

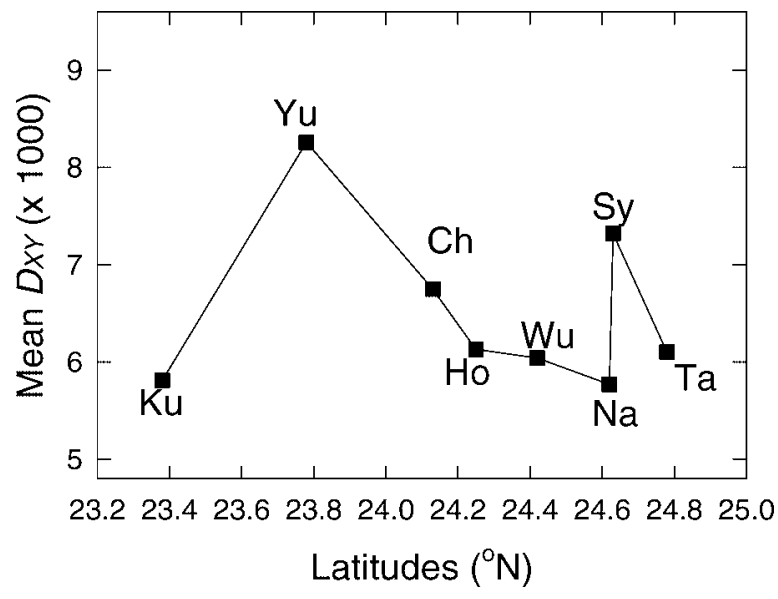

Fig. 2. Plot of the mean $D_{\mathrm{XY}}$ values of each population compared with every other population against the population latitude in Abies kawakamii using $\mathrm{GapC}$ sequences. Population codes are labeled according to Table 1.

peak decreased to low values for the Nanhutashan and Kuanshan (0.0058) populations. The paired $D_{\mathrm{XY}}$ values of the chloroplast $t r n L-t r n F$ intergenic spacer for each population compared against the remaining populations were one order of magnitude lower than those of $G a p C$ values $\left(D_{\mathrm{XY}}=0.2-0.5 \times\right.$ $\left.10^{-4}\right)$. Hsuehshan again was the population with the highest value. Genetic divergence among populations was generally fairly small, and Hsuehshan was the only location common to both chloroplast and nuclear DNA sequences.

Zones of sharp genetic change-To investigate the genetic structure of Taiwan fir in greater detail, we applied SAMOVA algorithms to define groups and find the location of the most important genetic uniqueness among the eight populations. Table 6 gives the composition of the corresponding groups of populations inferred by the algorithms, their associated fixation indices, and their significance evaluated by permuting the populations without considering their geographical position (Excoffier et al., 1992). In the two-group case, Hsuehshan (Sy) was separated from the remaining A. kawakamii populations under investigation, yielding a $7.92 \%$ intergroup variance for the $G a p C$ marker; however, this value was not significant $(P>$ 0.05). By assuming that three populations are associated and grouping them together $(\mathrm{Sy} / \mathrm{Yu} / \mathrm{Ta}, \mathrm{Wu}, \mathrm{Ho}, \mathrm{Ch}, \mathrm{Na}$, and $\mathrm{Ku})$, we found that the three-group assumption had the greatest

TABLE 5. Estimates of haplotype diversity $(h)$, nucleotide diversity $(\pi)$, and test statistics of selection for Taiwanese populations of Abies kawakamii according to mutations in the $G a p C$ intron.

\begin{tabular}{|c|c|c|c|c|c|c|c|}
\hline Population & $\begin{array}{c}\text { No. } \\
\text { sequences }\end{array}$ & $\begin{array}{c}\text { No. } \\
\text { haplotypes }\end{array}$ & Haplotype diversity $(h)$ & Nucleotide diversity $(\pi)$ & $D$ & $D^{*}$ & $F^{*}$ \\
\hline Taiwan & 122 & 10 & $0.780 \pm 0.023$ & $0.00648 \pm 0.00065$ & -0.24877 & 1.39979 & 0.91182 \\
\hline $\mathrm{Ta}$ & 16 & 7 & $0.842 \pm 0.059$ & $0.00542 \pm 0.00148$ & -1.08653 & -1.62025 & -1.69542 \\
\hline Sy & 16 & 6 & $0.783 \pm 0.085$ & $0.00730 \pm 0.00170$ & 0.16672 & 0.83024 & 0.74399 \\
\hline $\mathrm{Na}$ & 16 & 6 & $0.750 \pm 0.078$ & $0.00491 \pm 0.00140$ & -1.16207 & -2.15816 & -2.16691 \\
\hline $\mathrm{Wu}$ & 12 & 6 & $0.818 \pm 0.084$ & $0.00570 \pm 0.00174$ & -1.10118 & -1.75900 & -1.80591 \\
\hline Ho & 16 & 5 & $0.683 \pm 0.091$ & $0.00598 \pm 0.00186$ & -1.33477 & -1.92511 & -2.02895 \\
\hline $\mathrm{Ch}$ & 16 & 5 & $0.733 \pm 0.079$ & $0.00738 \pm 0.00193$ & -0.71622 & -0.32392 & -0.49960 \\
\hline $\mathrm{Yu}$ & 14 & 6 & $0.835 \pm 0.070$ & $0.00982 \pm 0.00161$ & -0.03590 & -0.13603 & -0.12485 \\
\hline $\mathrm{Ku}$ & 16 & 6 & $0.742 \pm 0.084$ & $0.00486 \pm 0.00140$ & -1.18511 & -2.15816 & -2.17427 \\
\hline
\end{tabular}

Note: $D, D$ test of Tajima (1989); $D^{*}, \mathrm{Fu}$ and $\mathrm{Li}(1993) ; F^{*}, \mathrm{Fu}$ and $\mathrm{Li}(1993)$. See Table 1 for full names of populations. 
TABLE 6. Fixation indices corresponding to groups of populations inferred by SAMOVA algorithms for Abies kawakamii populations in Taiwan tested for the GapC introns and for chloroplast trnL-trnF intergenic spacers.

\begin{tabular}{ccllc}
\hline \hline Marker & Group & \multicolumn{1}{c}{ Population groupings } & \multicolumn{1}{c}{$F_{\text {Ст }}$} & $P$ \\
\hline \multirow{2}{*}{ GapC } & 2 & Sy/Yu, Ta, Wu, Ho, Ch, Na, Ku & 0.07917 & 0.12708 \\
& 3 & Sy/Yu/Ta, Wu, Ho, Ch, Na, Ku & 0.09967 & 0.04301 \\
& 4 & Sy/Yu/Ta/Wu, Ho, Ch, Na, Ku & 0.08361 & 0.01466 \\
& 5 & Sy/Yu/Ta/Ho, Ch/Na, Wu, Ku & 0.07719 & 0.00098 \\
& 6 & Sy/Yu/Ta/Wu/Ho, Ch/Na, Ku & 0.07367 & 0.00782 \\
$\operatorname{trnL-trnF}$ & 2 & Sy/Ta, Yu, Wu, Na, Ho, Ch, Ku & 0.1003 & 0.12708 \\
& 3 & Sy/Ta, Yu, Wu/Na, Ho, Ch, Ku & 0.1194 & 0.00293 \\
& 4 & Sy/Ta, Yu, Wu/Na, Ho, Ch/Ku & 0.1058 & 0.01075 \\
& 5 & Sy/Ta, Yu, Wu/Na, Ho/Ch/Ku & 0.1009 & 0.00391 \\
\hline
\end{tabular}

variance among groups and resulted in a statistically maximal variance $(9.97 \%, P<0.05)$. This conforms to the result from the pairwise $D_{\mathrm{XY}}$ study. The four-group assumptions $(\mathrm{Sy} / \mathrm{Yu} /$ $\mathrm{Ta} / \mathrm{Wu}, \mathrm{Ho}, \mathrm{Ch}, \mathrm{Na}$, and $\mathrm{Ku}$ ) also resulted in a statistically significant variance $(8.36 \%, P<0.05)$. The five- and six-group assumptions, although significant, had less differentiation.

SAMOVA was also applied to the cpDNA sequences. The three-group assumptions ( $\mathrm{Sy} / \mathrm{Ta}, \mathrm{Yu}, \mathrm{Wu} / \mathrm{Na}, \mathrm{Ho}, \mathrm{Ch}, \mathrm{Ku}$ ) had the greatest variance among groups and resulted in a statistically maximum variance $\left(F_{\mathrm{CT}}=0.1194, P<0.01\right)$. The four- and five-group assumptions also resulted in statistically significant variances but with lower percentages of variance (Table 6).

\section{DISCUSSION}

The GapC genealogical tree showed that several species of Abies have mixed haplotypes, contrary to what would be expected of alleles assumed to have become species specific. This is probably not due to hybridization/introgression between distantly distributed species because the same condition was observed among three Japanese species of Abies (Isoda and Shiraishi, 2001). The mixture of haplotypes among different species might be due to incomplete lineage sorting; thus, the GapC gene tree does not accurately reflect the species tree. A potential cause of noncoalescence is incorrect taxonomy. But this is not applicable to A. kawakamii because morphological distinctness was confirmed by Liu (1971). We believe that the sequence polymorphism found in the GapC intron is consistent with allelic divergence predating the speciation of Abies in Asia. This result is congruent with the findings of Bouille and Bousquet (2005) for the genus Picea in which intraspecific- as well as transspecific-shared polymorphisms were detected in the DNA among three distantly related species.

Characteristics of the genetic structure of populationsThe genetic diversity of Taiwan fir is extremely low in terms of both mtDNA and cpDNA sequences, but is moderate in nuclear DNA $(\pi=0.00648)$. Populations of Taiwan fir are characterized by a uniform distribution of genetic diversity. Populations have similar numbers of haplotypes, and most of the haplotypes are widely distributed. This uniform genetic diversity results in low genetic differentiation among populations. Few population-specific haplotypes exist because of exchanges of genetic information between refugia. Even though species of Abies have very long generation times and heavy pollen grains, they apparently are able to establish highly efficient pollen-mediated gene flow between distant sites (Liepelt et al., 2002). Our observations indicated that refuge sites of Taiwan fir slightly differ from refugial areas in temperate regions that have high molecular diversity and a high proportion of unique alleles based on many studies of European plants and animals (see references in Comes and Kadereit, 1998).

We detected some similarities with several Abies species having fragmented ranges and small isolated populations. The average heterozygosity $\left(H_{\mathrm{O}}\right)$ of Abies in southern Mexico and Guatemala (A. flinckii, A. guatemalensis, A. hickeli, and A. religiosa) is lower than the range reported for most conifers (0.069-0.113, Aguirre-Planter, 2000), whereas differentiation among populations is higher than that observed in most conifer species studied $\left(F_{\mathrm{ST}}\right.$, the proportion of total genetic diversity among populations, 0.073-0.271). Populations of Mexican spruce (Picea mexicana Martínez), an endangered species in Mexico, are widely separated, and the $F_{\mathrm{ST}}$ was 0.069 (Ledig et al., 2002), while moderate genetic diversity $\left(H_{\mathrm{E}}=0.125\right)$ was maintained. A similar situation also occurs with Pinus nelsonii, a relictual pinyon pine distributed across a wide elevational range in semiarid zones of Mexico that has low to moderate population differentiation (Cuenca et al., 2003). The presentday Iberian distribution of Scots pine (Pinus sylvestris L.) conforms to a warm-stage pattern, with fragmented populations sheltering at isolated high elevations on different mountain chains. Scots pine maintains high within-population and low among-population diversities for neutral genetic markers (Robledo-Arnuncio et al., 2005). Thus, in most of those studies, relictual conifers have moderate differentiation among populations. There is a strong correlation between genetic differentiation and the geographic extent of the sampling. The species studied in a restricted area had a lower $G_{\text {ST }}$ value compared to those studied across a larger fraction of the species' range (Petit et al., 2005). Because A. kawakamii is a narrow endemic, its small range is a potential factor influencing $G_{\text {ST. }}$.

Petit et al. (2005) compiled studies of genetic structure based on three genomes in seed plants and concluded that in conifers, paternally and biparentally inherited markers also have very similar levels of genetic structure, as shown by the relatively tight positive correlation between the two sets of $G_{\text {ST }}$ estimates. There is more heterogeneity in $G_{\mathrm{ST}}$ estimates based on paternally inherited markers than for those based on biparentally inherited ones. Hence, $G_{\mathrm{ST}}$ values at cpDNA markers will reach equilibrium faster than $G_{\mathrm{ST}}$ values at nuclear genes, resulting in transient situations in which the $G_{\mathrm{ST}}$ of paternally inherited genes is smaller than the $G_{\mathrm{ST}}$ of biparentally inherited genes. This may explain how the paired $D_{\mathrm{XY}}$ values of chloroplast DNA for each population compared against the remaining populations were smaller than those of GapC values in this study.

Phylogeographical structure-In theory, the phylogeographical structure is expected to be less pronounced at diploid nuclear loci compared with cytoplasmic loci because of their different effective population sizes (McCauley, 1995; Moore, 1995). In addition, a clear picture of migration did not emerge from the nuclear DNA analysis. This may have been due to the increased likelihood of encountering incomplete lineage sorting with nuclear genes, which have a greater expected coalescence 
time than do organelle genes (Avise, 2000). In this study, however, cpDNA had little nucleotide diversity, and a clear route of retreat was not obvious. Pinaceae species are known to have paternal inheritance of their chloroplast genome (Mogensen, 1996). Even though the phylogeographic structure can be obtained from paternally inherited cpDNA (RobledoArnuncio et al., 2005; Walter and Epperson, 2005), this cpDNA has generally obscured information about migration routes. The effective role of pollen flow in homogenizing the genetic structure of Scots pine has eroded the genetic imprints of its population history (Robledo-Arnuncio et al., 2005) that maternally inherited mtDNA markers seem to retain ( $\mathrm{Hu}$ and Ennos, 1999).

A star-like distribution of haplotypes indicating population expansion was shown by Tajima's $D$ test for several local subtropical and montane species: Quercus glauca (Huang et al., 2002), Cunninghamia konishii (Chung et al., 2004), Castanopsis carlesii (Cheng et al., 2005), and Machilus thunbergii (Wu et al., 2006). The selective neutrality for the nuclear GapC fragment and cpDNA shown for Taiwan fir, however, had no evidence of population expansion and may be another important characteristic of refuge populations. This outcome probably resulted from a demographic history of rapid contraction that eliminated most of the diversity. A similar situation was found for relictual species of Maxipiñon (Pinus maximartinezii) (Ledig et al., 1999) and Martínez spruce (Picea martinezii) (Ledig et al., 2000). Both species occur in only one or a few locations in Mexico, and genetic diversity measured by expected heterozygosity was moderate (around 0.120). Significant gametic disequilibrium is in agreement with an origin from an extreme bottleneck (Ledig et al., 1999).

Population divergence-The degree of average genetic divergence of each population in comparison with the remaining populations can be used to examine the consequence of historical and contemporary geographical population subdivisions on evolutionary processes (Johnson et al., 2000) and is important for reconstructing phylogeographical histories that have evolved during pre- and postcolonization events (Grant and Grant, 1997). Each population of common ivy and of other species in Europe were genetically differentiated from the remaining populations $\left(F_{\mathrm{ST}}\right)$ as revealed by a latitudinal pattern, with populations from the south significantly more differentiated from the pooled remaining populations than were either the central or northern populations (Grivet and Petit, 2002; Petit et al., 2003). Thus, population divergence or genetic differentiation can be a useful criterion for locating likely glacial refugia.

In our study, small genetic divergences, in terms of $D_{\mathrm{XY}}$, of each population from the remaining populations were found for both markers, particularly the chloroplast DNA marker. Upon closer examination, the mean values of pairwise $D_{\mathrm{XY}}$ for each population when compared against the remaining populations revealed that the common divergent population for both markers was situated in a single location: Hsuehshan. The potential refugia deduced from the extant pattern of genetic diversity for Trochodendron aralioides (Huang et al., 2004), Cunninghamia konishii (Chung et al., 2004), Castanopsis carlesii (Cheng et al., 2005), and Machilus thunbergii (Wu et al., 2006) also occur at a latitude identical to that of the Hsuehshan Range.

Results of SAMOVA allowed us to identify maximally differentiated population groups. The three-group assumptions had the greatest variance found among groups for both the GapC and trnL-trnF sequences. This also led to the identification of genetic barriers between Hsuehshan/Yushan and the remaining populations. This result supports the uniqueness of the Hsuehshan population and possibly of the Yushan population as suggested by the results of the genetic divergence $\left(D_{\mathrm{XY}}\right)$ study. Taiwan fir populations at Hsuehshan and Yushan represent subalpine regions that still contain broad areas of pure stands (Fig. 1). It seems likely that, during a range change, retreating edges suffered shrinkage, dissection, and extinction, such that the last surviving populations are likely to be severely bottlenecked.

\section{LITERATURE CITED}

Аввott, R. J., And C. Brochman. 2003. History and evolution of the Arctic flora: in the footsteps of Eric Hulten. Molecular Ecology 12: 299313.

Aguirre-Planter, E., G. R. Furnier, and L. E. Eguiarte. 2000. Low levels of genetic variation within and high levels of genetic differentiation among populations of species of Abies from southern Mexico and Guatemala. American Journal of Botany 87: 362-371.

Avise, J. C. 2000. Phylogeography: the history and formation of species. Harvard University Press, Cambridge, Massachusetts, USA.

Boggs, S., W. C. Wang, F. S. Lewis, and J. C. Chen. 1979. Sediment properties and water characteristics of the Taiwan shelf and slope. Acta Oceanographic of Taiwan 10: 10-49.

Bonnet, E., AND Y. VAN DE PeER. 2002. zt: a software tool for simple and partial Mantel tests. Journal of Statistical Software 7: 1-12.

BouILLE, M., AND J. BousQuet. 2005. Trans-species shared polymorphisms at orthologous nuclear gene loci among distant species in the conifer Picea (Pinaceae): implications for the long-term maintenance of genetic diversity in trees. American Journal of Botany 92: 63-73.

Caicedo, A. L., and B. A. Schaal. 2004. Population structure and phylogeography of Solanum pimpinellifolium inferred from a nuclear gene. Molecular Ecology 13: 1871-1882.

Cheng, Y. P., S. Y. Hwang, and T. P. Lin. 2005. Two potential refugia in Taiwan revealed by the phylogeographical study of Castanopsis carlesii Hayata (Fagaceae). Molecular Ecology 14: 2075-2085.

Chung, J. D., T. P. Lin, Y. C. TAN, M. Y. Lin, and S. Y. Hwang. 2004. Genetic diversity and biogeography of Cunninghamia konishii (Cupressaceae), an island species in Taiwan: a comparison with Cunninghamia lanceolata, a mainland species in China. Molecular Phylogenetics and Evolution 33: 791-801.

Comes, H. P., AND J. W. KADEREIT. 1998. The effect of Quaternary climatic changes on plant distribution and evolution. Trends in Plant Sciences 3: 432-438.

Cuenca, A., A. E. Escalante, and D. Pinero. 2003. Long-distance colonization, isolation by distance, and historical demography in a relictual Mexican pinyon pine (Pinus nelsonii Shaw) as revealed by paternally inherited genetic markers (cpSSRs). Molecular Ecology 12: 2087-2097.

Demesure, B., N. Sodzi, and R. J. Petit. 2000. A set of universal primers for amplification of polymorphic non-coding regions of mitochondrial and chloroplast DNA in plants. Molecular Ecology 4: 129-131.

Dupanloup, I., S. Schneider, And L. Excoffier. 2002. A simulated annealing approach to define the genetic structure of populations. Molecular Ecology 11: 2571-2581.

Excoffier, L., P. E. Smouse, and J. M. Quattro. 1992. Analysis of molecular variance inferred from metric distances among DNA haplotypes: application to human mitochondrial DNA restriction data. Genetics 131: 479-491.

Fu, Y. X., AND W. H. Li. 1993. Statistical tests of neutrality of mutations. Genetics 133: 693-709.

Grant, P. R., and B. R. Grant. 1997. Genetics and origin of bird species. Proceedings of the National Academy of Sciences, USA 94: 77687775.

Grivet, D., And R. J. Petit. 2002. Phylogeography of the common ivy 
(Hedera sp.) in Europe: genetic differentiation through space and time. Molecular Ecology 11: 1351-1362.

HARE, M. P. 2001. Prospects for nuclear gene phylogeography. Trends in Ecology and Evolution 16: 700-706.

HewitT, G. 2000. The genetic legacy of the Quaternary ice ages. Nature 405: 907-913.

Hu, X. S., AND R. EnNos. 1999. Impacts of seed and pollen flow on population genetic structure for plant genomes with three contrasting modes of inheritance. Genetics 152: 441-450.

HuANG, K. Y. 2002. Evaluation of the topographic sheltering effects on the spatial pattern of Taiwan fir using aerial photography and GIS. International Journal of Remote Sensing 23: 2051-2069.

Huang, S. F., S. Y. Hwang, J. C. Wang, and T. P. Lin. 2004. Phylogeography of Trochodendron aralioides (Trochodendraceae) in Taiwan and its adjacent areas. Journal of Biogeography 31: 12511259.

Huang, S. S. F., S. Y. Hwang, and T. P. Lin. 2002. Spatial pattern of chloroplast DNA variation of Cyclobalanopsis glauca in Taiwan and east Asia. Molecular Ecology 11: 2349-2358.

Hudson, R. R., AND N. L. Kaplan. 1995. Deleterious background selection with recombination. Genetics 141: 1605-1617.

IsODA, K., AND S. SHIRAISHI. 2001. Allelic sequence polymorphisms in the intron region of the nuclear-encoded GapC gene preceded the speciation of three closely related Abies species (Pinaceae). Theoretical and Applied Genetics 102: 244-250.

Johnson, K. P., F. R. Adler, and J. L. Cherry. 2000. Genetic and phylogenetic consequences of island biogeography. Evolution 54: 387-396.

JuKES, T. H., AND C. R. CANTOR. 1969. Evolution of protein molecules. In H. N. Munro [ed.], Mammalian protein metabolism, 21-132. Academic Press, New York, New York, USA.

KimuRA, M. 1996. Quaternary paleogeography of the Ryukyu Arc. Journal of Geography 105: 259-285 (in Japanese with English abstract).

KormutaK, A., And J. C. Yang. 1998. The genetics and embryology of Taiwan fir (Abies kawakamii (Hayata) Ito). Taiwan Journal of Forest Science 13(1): Monograph 1.

Ledig, F. T., B. Bermejo-Velázquez, P. D. Hodgskiss, D. R. Johnson, C. Flores-López, and V. JaCoB-Cervantes. 2000. The mating system and genic diversity in Martínez spruce, an extremely rare endemic of México's Sierra Madre Oriental: an example of facultative selfing and survival in interglacial refugia. Canadian Journal of Forest Research 30: $1156-1164$.

Ledig, F. T., M. T. Conkle, B. Bermejo-Velazquez, T. Eguiluz-Piedra, P. D. Hodgskiss, D. R. Johnson, AND W. S. DvoraK. 1999. Evidence for an extreme bottleneck in a rare Mexican pinyon: genetic diversity, disequilibrium, and mating system in Pinus maximartinezii. Evolution 53: 91-99.

Ledig, F. T., P. D. Hodgskiss, and V. Jacob-Cervantes. 2002. Genetic diversity, mating system, and conservation of a Mexican subalpine relict, Picea mexicana Martínez. Conservation Genetics 3: 113-122.

Liepelt, S., R. Bialozyt, and B. Ziegenhagen. 2002. Wind-dispersed pollen mediates postglacial gene flow among refugia. Proceedings of the National Academy of Sciences, USA 999: 14590-14594.

Liu, T. S. 1971. A monograph of the genus Abies. Department of Forestry, National Taiwan University, Taipei, Taiwan.

McCAuley, D. E. 1995. The use of chloroplast DNA polymorphism in studies of gene flow in plants. Trends in Ecology and Evolution 10: 198-202.

Mogensen, H. L. 1996. The hows and whys of cytoplasmic inheritance of seed plants. American Journal of Botany 83: 383-404.

Mooke, W. S. 1995. Inferring phylogenies from mtDNA variation: mitochondrial-gene trees versus nuclear-gene trees. Evolution 49: $718-726$.

Murray, M. G., and W. F. Thompson. 1980. Rapid isolation of high molecular weight plant DNA. Nucleic Acids Research 8: 4321-4325.

NeI, M. 1987. Molecular evolutionary genetics. Columbia University Press, New York, New York, USA.

Okuyama, Y., N. Fuji, M. Wakabayashi, A. Kawakita, Ito, M. Watanabe, N. Murakami, and M. Kato. 2005. Nonuniform concerted evolution and chloroplast capture: heterogeneity of observed introgression patterns in three molecular data partition phylogenies of Asian Mitella (Saxifragaceae). Molecular Biology and Evolution 22: 285-296.

Olsen, K. M., AND B. A. SchaAl. 1999. Evidence on the origin of cassava: phylogeography of Manihot esculenta. Proceedings of the National Academy of Sciences, USA 96: 5586-5591.

Parducci, L., A. E. Szmidt, A. Madaghiele, M. Anzidei, and G. G. VendRAmin. 2001. Genetic variation at chloroplast microsatellites (cpSSRs) in Abies nebrodensis (Lojac.) Mattei and three neighboring Abies species. Theoretical and Applied Genetics 102: 733-740.

Petit, R. J., I. Aguinagalde, J. L. De Beaulieu, C. Bittkau, S. Brewer, R. Cheddadi, R. Ennos, S. Fineschi, D. Grivet, M. Lascoux, A. Mohanty, G. Muller-Starck, B. Demesure-Musch, A. Palme, J. P. Martin, S. Rendell, and G. G. Vendramin. 2003. Glacial refugia: hotspots but not melting pots of genetic diversity. Science 300: $1563-$ 1565.

Petit, R. J., E. Duminil, S. Fineschi, A. Hampe, D. Salvini, and G. G. VENDRAMIN. 2005. Comparative organization of chloroplast, mitochondrial and nuclear diversity in plant populations. Molecular Ecology 14: 689-701.

Pielou, E. C. 1991. After the ice age. University of Chicago Press, Chicago, Illinois, USA.

Pons, O., AND R. J. Petit. 1996. Measuring and testing genetic differentiation with ordered versus unordered alleles. Genetics 144: $1237-1245$.

Robledo-Arnuncio, J. J., C. Collada, R. Alia, and L. Gil. 2005. Genetic structure of montane isolates of Pinus sylvestris L. in a Mediterranean refugial area. Journal of Biogeography 32: 595-605.

Rozas, J., J. C. Sànchez-DelBarrio, X. Messequer, and R. Rozas. 2003. DnaSP, DNA polymorphism analyses by the coalescent and other methods. Bioinformatics 19: 2496-2497.

Schierup, M. H., AND J. HeIN. 2000. Consequences of recombination on traditional phylogenetic analysis. Genetics 156: 879-891.

Suyama, Y., H. Yoshimaru, and Y. Tsumura. 2000. Molecular phylogenetic position of Japanese Abies (Pinaceae) based on chloroplast DNA sequences. Molecular Phylogenetics and Evolution 16: 271-277.

TABeRLET, P., AND R. ChedDADI. 2002. Quaternary refugia and persistence of biodiversity. Science 297: 2009-2010.

Taiwan Forest Bureau/Anonymous. 1995. The third forest resources and land use inventory in Taiwan. Taiwan Forest Bureau, Taiwan Province, Council of Agriculture, Taipei, Taiwan (in Chinese).

Tajima, F. 1989. Statistical method for testing the neutral mutation hypothesis by DNA polymorphism. Genetics 123: 585-595.

Tani, N., Y. Tsumura, AND H. SATo. 2003. Nuclear gene sequences and DNA variation of Cryptomeria japonica samples from postglacial period. Molecular Ecology 12: 859-868.

Templeton, A. R., K. A. Crandall, and C. F. Sing. 1992. A cladistic analysis of phenotypic associations with haplotypes inferred from restriction endonuclease mapping and DNA sequence data. III. Cladogram estimation. Genetics 132: 619-633.

Thompson, J. D., G. D. Higgins, and T. J. Gibson. 1994. ClustalW: improving the sensitivity of progressive sequence alignment through sequence weighting, position-specific gap penalties and weight matrix choice. Nucleic Acids Research 22: 4673-4680.

Tsukada, M. 1966. Late Pleistocene vegetation and climate in Taiwan (Formosa). Proceedings of the National Academy of Sciences, USA 55: 543-548.

TsuKadA, M. 1967. Vegetation in subtropical Formosa during the Pleistocene glaciation and the Holocene. Palaeogeography, Palaeoclimatology, Palaeoecology 3: 49-64.

Walter, R., AND B. EpPerson. 2005. Geographic pattern of genetic diversity in Pinus resinosa: contact zone between descendants of glacial refugia. American Journal of Botany 92: 92-100.

Wolfe, K. H., W. H. Li, and P. M. Sharp. 1987. Rates of nucleotide substitution vary greatly among plant mitochondrial, chloroplast, and nuclear DNAs. Proceedings of the National Academy of Sciences, USA 84: 9054-9058. 
Wu, S. H., C. Y. Hwang, T. P. Lin, J. D. Chung, Y. P. Cheng, and S. Y. Hwang. 2006. Contrasting phylogeographic patterns of two closely related species, Machilus thunbergii and Machilus kusanoi (Lauraceae), in Taiwan. Journal of Biogeography 33: 936-947.

Xiang, Q. P., Q. Y. Xiang, A. Liston, and X. C. Zhang. 2004.
Phylogenetic relationships in Abies (Pinaceae): evidence from PCRRFLP of the nuclear ribosomal DNA internal transcribed spacer region. Botanical Journal of the Linnean Society 145: 425-435.

Zhang, D. X., AND G. M. HewitT. 2003. Nuclear DNA analyses in genetic studies of populations: practice, problems and prospects. Molecular Ecology 12: 563-584. 